\title{
Is pregnancy order a factor in epilepsy?
}

\author{
JULIUS D. METRAKOS AND KATHERINE METRAKOS \\ From the Department of Genetics, McGill University, and the Department of Medical \\ Genetics, the Montreal Children's Hospital, Montreal, Canada
}

From surveying the literature, one would surmise that opinion at the moment is divided, more or less equally, on the question of whether or not 'parity' is aetiologically linked with epilepsy. Among those who say yes, the majority claim that it is the first born that is most likely to be affected; however, a few claim that it is the later born who are more apt to suffer trauma at birth and therefore develop epilepsy. Unfortunately, none of the above studies are comparable with one another, for wide differences may be found between them in one or more of the following five pertinent considerations: 1 Definition of factor to be studied, 2 type of epilepsy studied, 3 method of ascertaining index cases, 4 selection of controls, and 5 method of evaluating parity. Because of these manifold differences it is not a paradox to say that possibly all of these studies may be correct. However, insofar as contradictory answers to the same question cannot both be correct, the question is worth reexamination.

The debate concerning parity as a factor in epilepsy has been raging actively for at least 50 years. Those who have investigated and reported the subject tend to hold tacitly to their original conclusions, for or against. The majority of those who are interested in the answer but who have not contributed original data appear to abide by whatever happens to be the last published report, for or against.

Most recently, Colver and Kerridge (1962) reviewed some of the studies, difficulties, and controversies alluded to above, and, from their own data of 174 cases of central (21), focal (45), or undifferentiated (108) epileptics who had suffered 10 or more 'convulsion days' concluded that 'it has been established beyond reasonable doubt that epilepsy as defined above is more frequent in first than in second born children'. These investigators cautiously suggest that their results 'taken with the similar birth order differences among stillbirths and deaths in the first week of life are at least consistent with the hypothesis that these occurrences and epilepsy in childhood may have important causes in common'. The Lancet (1962) went further and annotated that 'some will find in Colver and

${ }^{1}$ The choice of this word will be explained later.
Kerridge's results support for Penfield's concept of incisural epilepsy-due to trauma to the medial aspects of the temporal lobes by herniation through the tentorial hiatus during pressure on the skull at birth-as a common source of the so-called idiopathic disease'.

If it is true, as Colver and Kerridge, the Lancet, and many others have suggested, that parity has such far-reaching implications, both theoretical and practical, then it becomes imperative to reach some better understanding and thereby to eliminate the periodic oscillation between for and against to the resolution: A person's parity affects his probability of getting epilepsy.

\section{THE MEANING OF 'BIRTH ORDER' ('PREGNANCY ORDER'?)}

When parity is investigated in epilepsy (or in some other condition) it is not parity as such that is important, but rather how it may reflect the physiopathological state of the maternal uterus plus a host of other ante- and perinatal factors. The reproductive history of a woman who has had, let us say, three miscarriages, two stillborn and one liveborn infants, is in no way comparable with that of a woman who has had only one pregnancy resulting in a living child. And yet, those who consider successful pregnancies only would accept these two women as alike. It appears essential, therefore, that investigations of parity should include all pregnancies of the mother, irrespective of whether they resulted in live infants (single or multiple), stillborns, or abortions (spontaneous or induced).

Without exception, all the papers on this subject that were reviewed by the present authors did not give due consideration to all pregnancies when evaluating parity but dealt primarily with pregnancies resulting in liveborn infants. Most did not even mention miscarriages. Among those that did, nearly all authors thought the problem to be of trivial importance and unworthy of the effort required to obtain the history of all pregnancies irrespective of their outcome.

In order to see how much of a difference it makes to the parity of the proband if miscarriages and 
stillbirths are omitted, we attempted to correlate birth order with pregnancy order. 'Birth order' refers to the birth order of liveborn offspring only. 'Pregnancy order' refers to the order of all pregnancies. Because the proband of most studies is usually a liveborn infant, we have reserved the term 'parity' to refer to his ordinal position without clarifying whether all pregnancies are being considered or not. In this context, therefore, pregnancy order refers to the chronological order of each pregnancy of the proband's mother, irrespective of type (single, twin, triplet) or outcome (liveborn, miscarriage, ectopic). It includes illegitimate pregnancies and pregnancies of all marriages. To avoid further confusion, from this point on the terms 'pregnancy order' and 'birth order' will convey only the meaning just assigned to them. The term 'parity' will continue to be used in its original non-specific sense.

In Table I the birth order and pregnancy order of 1,279 probands are given. (The reason and method of ascertaining these probands are explained in a later section.) Birth order agrees with pregnancy order in only 993 cases. In the other 286 cases $(22.4 \%)$ there is no agreement. It appears, therefore, that if successful pregnancies only are considered pregnancy order is wrongly classified in approximately one case in four. Furthermore, as could be anticipated, because of the cumulative effect, the error in classification increases as the pregnancy order of the proband increases. For example, for birth order I the error is $12.1 \%$, for birth order II, $21.4 \%$, for birth order III, $34.6 \%$, and so on, so that by birth order VII an error in classification occurs more than half of the time. It follows, therefore, that when liveborn pregnancies only are considered the mean 'family size' is numerically smaller than the mean pregnancy number which is here designated by s. The effect of this is that the lower birth-order ranks are over-represented and the higher ranks are underrepresented by an equal amount. If one looks at the totals for birth order and pregnancy order a simple calculation will show that birth orders I to III overrepresent pregnancy orders 1 to 3 by 100 cases; and, of course, birth orders IV to XVI under-represent pregnancy orders 4 to 17 by 100 cases. In our data this transition from over-representation to underrepresentation occurred between ranks III and IV. Where it will occur in other data will depend upon the mean of $s$.

TABLE I

PERCENTAGE MISCLASSIFICATION IN PREGNANCY ORDER FOR LIVEBORN PREGNANCIES ONLY

Pregnancy Order (All Pregnancies)

\begin{tabular}{lllllllllllllllllll}
\hline 1 & 2 & 3 & 4 & 5 & 6 & 7 & 8 & 9 & 10 & 11 & 12 & 13 & 14 & 15 & 16 & 17 & Total & Percentage
\end{tabular} 
It seems to us that the large error in percentage misclassification when liveborn pregnancies only are considered plus the resultant over-representation for lower ranks and under-representation for higher ones is sufficient by itself to cast serious doubts on any conclusions regarding parity derived from such studies. On this we are in complete agreement with Haldane and Smith (1948) who noted that 'unrecorded miscarriages and stillbirths always makes birth rank data somewhat unreliable'. To invoke errors due to the subtleties and niceties of type of epilepsy, ascertainment, controls, and method of analysis would be superfluous when the data are not representative of the factor to be studied.

\section{ESTIMATION OF BIRTH ORDER EFFECT (PREGNANCY ORDER EFFECT?)}

What does it mean when one says that an epileptic proband is first born, second born, or nth born? From the above discussion, and from the present data, we have seen that on the average it may ( $77.6 \%$ of the time) or may not $(22.4 \%$ of the time) mean that the epileptic proband was the product of the first, second, or nth pregnancy. Furthermore, whether birth order is or is not in agreement with pregnancy order, the significance of the answer to our question depends on the size of s. For example, if the epileptic proband is labelled first born and $s=1$, then there is no alternative but for the proband to be first born. However, if $s=10$, and epileptic probands are distributed randomly, then there is only one chance in ten that the proband would be first born. Needless to say, if the mean and standard error of $s$ is not the same for two different studies, their results are not strictly comparable.

In evaluating parity, the mean size and range of $s$ is, in many ways, even more important than the distinction between birth order and pregnancy order. Yet, in far too many reports this is not taken into consideration. It means nothing to say that in a large study over $50 \%$ of epileptics were first born, if in approximately $50 \%$ of the families $s=1$. The smaller the mean of $s$ is, the higher will be the proportion of first born.

As early as 1914, Greenwood and Yule reported what has come to be known as the Greenwood-Yule method of testing for parity effect. It has been used for testing for birth order effect and for pregnancy order effect. Halperin (1953), McKeown and Record (1956), and others have shown that the method is not completely free of faults; however, it has certain advantages which have made it a popular test.

In brief, the Greenwood-Yule method treats each family size separately and notes whether the pro- band is randomly distributed with respect to pregnancy order. For example (and within certain limitations), if pregnancy order is not a factor, then when $s=2$, the proband is the result of pregnancy order 1 in $50 \%$ of the time; when $s=3$, in $33 \%$; when $s=4$, in $25 \%$; and so on. Needless to repeat, families where $s=1$ do not contribute any information when the Greenwood-Yule method is used. The two chief advantages here are that the proportions of the different family sizes become relatively unimportant, and the experimental families can be tested within themselves without necessitating control data.

\section{CONSTRUCTIVE CONTRIBUTION}

With certain minor modifications, and remembering that $s$ equals the number of pregnancies irrespective of their outcome, we have analysed the pregnancy order of 1,279 epileptic and non-epileptic probands by the Greenwood-Yule method. These are the same probands whose birth order/pregnancy order relationship was compared in Table $\mathrm{I}$. They have been collected in connexion with our study of genetic factors in convulsive disorders. They fall into two general categories.

CONVULSANT PROBANDS $(\mathrm{N}=986)$ These are patients who come to the Neurology Service of the Montreal Children's Hospital with a history of having had at least one convulsive episode. They are subdivided into a number of classes according to two major criteria based upon the clinical and electroencephalographic diagnoses.

NON-CONVULSANT PROBANDS $(\mathrm{N}=293)$ These are patients of the same hospital population but without any history of convulsions.

When a suitable proband is found, convulsant or non-convulsant, a detailed family and medical history is taken by interviewing the parents. The mother is particularly questioned about her reproductive history. Information is obtained about each one of her pregnancies irrespective of their outcome.

In Table II, the pregnancy order of 986 probands who present a history of having had at least one bone fida convulsion is analysed for pregnancy order effect. The results clearly indicate that the pregnancy order of these convulsant probands is randomly distributed for the cumulative $\chi^{2}(13 \cdot 39)$, for 8 d.f. gives $P=0 \cdot 10$, that is, there is no evidence for any pregnancy order effect.

Similarly in Table III, the pregnancy order of 293 probands who have never had any convulsions is given and analysed for pregnancy order effect. Again, the pregnancy order of these non-convulsant 
TABLE II

PREGNANCY ORDER OF 986 PROBANDS (INCLUDING 99 HEMIPLEGICS WITH AT LEAST ONE CONVULSION) ${ }^{1}$

\begin{tabular}{|c|c|c|c|c|c|c|c|c|c|c|}
\hline \multirow[b]{2}{*}{$s$} & \multicolumn{10}{|c|}{ Pregnancy Order of Proband } \\
\hline & $I$ & 2 & 3 & 4 & 5 & 6 & 7 & 8 & 9 to 17 & Total \\
\hline 1 & $(82)$ & & & & & & & & & (82) \\
\hline 2 & 102 & 90 & & & & & & & & 192 \\
\hline 3 & 68 & 73 & 65 & & & & & & & 206 \\
\hline 4 & 34 & 48 & 52 & 54 & & & & & & 188 \\
\hline 5 & 22 & 11 & 16 & 22 & 29 & & & & & 100 \\
\hline 6 & 6 & 15 & 14 & 18 & 18 & 18 & & & & 89 \\
\hline 7 & 6 & 13 & 6 & 6 & 8 & 9 & 6 & & & 54 \\
\hline 8 & 2 & 1 & 2 & 3 & 1 & 3 & 7 & 6 & & 25 \\
\hline 9 to 20 & 1 & 3 & & 4 & 7 & 6 & 4 & 6 & 19 & 50 \\
\hline 0 & 241 & 254 & 155 & 107 & 63 & 36 & 17 & 12 & 19 & 904 \\
\hline e & 262.03 & 262.03 & 166.03 & $97 \cdot 36$ & $50 \cdot 36$ & $30 \cdot 36$ & $15 \cdot 53$ & $7 \cdot 82$ & 12.66 & $904 \cdot 18$ \\
\hline$x^{2}$ & $\begin{array}{l}1.69 \\
\end{array}$ & 0.25 & 0.73 & 0.95 & $3 \cdot 17$ & 1.05 & 0.14 & $2 \cdot 23$ & $3 \cdot 18$ & 13.39 \\
\hline
\end{tabular}

TABLE III

PREGNANCY ORDER OF 293 PROBANDS (INCLUDING 53 HEMIPLEGICS WITHOUT CONVULSIONS) ${ }^{1}$

Pregnancy Order of Proband

\begin{tabular}{|c|c|c|c|c|c|c|c|c|c|}
\hline$s$ & 1 & 2 & 3 & 4 & 5 & 6 & 7 & 8 to 13 & Total \\
\hline 1 & (18) & & & & & & & & (18) \\
\hline 2 & 32 & 30 & & & & & & & 62 \\
\hline 3 & 26 & 25 & 23 & & & & & & 74 \\
\hline 4 & 13 & 6 & 11 & 11 & & & & & 41 \\
\hline 5 & 7 & 5 & 7 & 10 & 9 & & & & 38 \\
\hline 6 & & & 2 & 4 & 5 & 4 & & & 15 \\
\hline 7 & 1 & 1 & 1 & 1 & 4 & 3 & 2 & & 13 \\
\hline 8 to 14 & 2 & 1 & 1 & 3 & 4 & 4 & 5 & 12 & 32 \\
\hline 0 & 81 & 68 & 45 & 29 & 22 & 11 & 7 & 12 & 275 \\
\hline e & $81 \cdot 39$ & $81 \cdot 39$ & $50 \cdot 39$ & $25 \cdot 72$ & 15.47 & $7 \cdot 87$ & $5 \cdot 37$ & $7 \cdot 39$ & 274.99 \\
\hline$x^{2}$ & 0.00 & $2 \cdot 20$ & 0.58 & 0.42 & $2 \cdot 76$ & $1 \cdot 24$ & 0.49 & $2 \cdot 88$ & 10.57 \\
\hline
\end{tabular}

probands appears to be randomly distributed 5 This group is the one presented in Table III: $(P=0 \cdot 10)$. The probands have no history of convulsions. It includes 53 hemiplegics without convulsions.

6 This group of probands has convulsions plus and non-convulsant probands, we have divided our material into the following 11 groups on the basis of clinical and electroencephalographic criteria. Depending on the number of criteria used, the groups may be distinct or they may overlap.

1 The only criterion used here was that the proband had at least one bone fide convulsion. This is the group whose pregnancy order has been analysed in detail in Table II. It includes 99 hemiplegics who had one or more convulsions concomitant with the hemiplegia.

2 This is group 1 but omitting the hemiplegics.

3 Two criteria were used here; in addition to a history of convulsions, the probands had an epileptiform E.E.G., focal or non-focal.

4 This is a highly specific group of chronic epileptics whose E.E.G. is of the centrencephalic type, i.e., bilaterally synchronous $3 / \mathrm{s}$ wave-and-spike or some variant of this. This is the group for which an irregular dominant gene has been postulated for the E.E.G. trait (Metrakos and Metrakos, 1961). a focal type of cerebral dysrhythmia. It includes hemiplegics who satisfy the two criteria.

7 This is group IV from which the typical centrencephalics have been omitted.

8 In a sense, this is the absolute control group, for the probands have no history of convulsions and the E.E.G. is normal or borderline normal.

9 This is group IV from which the atypical centrencephalics have been omitted.

10 This group is composed of hemiplegics who have convulsions concomitant with hemiplegia.

11 In a sense, this is the absolute experimental group, for the probands are brain-injured children whose cerebral palsy, in this case, hemiplegia, is substantiated by the presence of a focal electroencephalogram.

The 11 groups of convulsant and non-convulsant probands are listed in Table IV. In none of these groups was the pregnancy order of the proband found to be other than randomly distributed. 
TABLE IV

PREGNANCY ORDER OF 11 GROUPS OF CONVULSANT AND NON-CONVULSANT PROBANDS

\begin{tabular}{|c|c|c|c|c|c|c|c|c|c|c|c|c|c|}
\hline \multirow[t]{2}{*}{ Group } & & \multicolumn{10}{|c|}{ Pregnancy Order } & \multirow[t]{2}{*}{$d . f}$. & \multirow[t]{2}{*}{$\boldsymbol{P}$} \\
\hline & & 1 & 2 & 3 & 4 & 5 & 6 & 7 & 8 & $9-20$ & Total & & \\
\hline $\begin{array}{l}1 \text { Convulsions (including } \\
\text { hemiplegics) }\end{array}$ & $\begin{array}{l}0 \\
\mathrm{e} \\
\chi^{2}\end{array}$ & $\begin{array}{r}241 \\
262.03 \\
1.69\end{array}$ & $\begin{array}{r}254 \\
262.03 \\
0.25\end{array}$ & $\begin{array}{r}155 \\
166.03 \\
0.73\end{array}$ & $\begin{array}{r}107 \\
97.36 \\
0.95\end{array}$ & $\begin{array}{l}63 \\
50 \cdot 36 \\
3 \cdot 17\end{array}$ & $\begin{array}{l}36 \\
30.36 \\
1.05\end{array}$ & $\begin{array}{r}17 \\
15 \cdot 53 \\
0 \cdot 14\end{array}$ & $\begin{array}{l}12 \\
7 \cdot 82 \\
2 \cdot 23\end{array}$ & $\begin{array}{r}19 \\
12 \cdot 66 \\
3 \cdot 18\end{array}$ & $\begin{array}{l}904 \\
904 \cdot 18 \\
13 \cdot 39\end{array}$ & 8 & $0 \cdot 10$ \\
\hline $\begin{array}{l}2 \text { Convulsions (excluding } \\
\text { hemiplegics) }\end{array}$ & $\begin{array}{l}0 \\
\mathrm{e} \\
\chi^{2}\end{array}$ & $\begin{array}{l}214 \\
236 \cdot 41 \\
2 \cdot 12\end{array}$ & $\begin{array}{r}231 \\
236.41 \\
0.12\end{array}$ & $\begin{array}{r}142 \\
148.91 \\
0.32\end{array}$ & $\begin{array}{l}95 \\
86.91 \\
0.75\end{array}$ & $\begin{array}{l}56 \\
45 \cdot 41 \\
2 \cdot 47\end{array}$ & $\begin{array}{r}33 \\
27.61 \\
1.05\end{array}$ & $\begin{array}{l}15 \\
13 \cdot 78 \\
0 \cdot 11\end{array}$ & $\begin{array}{l}11 \\
6.92 \\
2.41\end{array}$ & $\begin{array}{l}16 \\
10 \cdot 83 \\
2.47\end{array}$ & $\begin{array}{c}813 \\
813 \cdot 19 \\
11 \cdot 82\end{array}$ & 8 & 0.20 \\
\hline $\begin{array}{l}3 \text { Convulsions plus } \\
\text { epileptiform E.E.G. }\end{array}$ & $\begin{array}{l}\mathbf{0} \\
\mathbf{e} \\
\chi^{2}\end{array}$ & $\begin{array}{r}148 \\
153.65 \\
0.21\end{array}$ & $\begin{array}{r}156 \\
153.65 \\
0.04\end{array}$ & $\begin{array}{l}94 \\
94 \cdot 15 \\
0 \cdot 00\end{array}$ & $\begin{array}{l}55 \\
56.82 \\
0.06\end{array}$ & $\begin{array}{l}27 \\
29 \cdot 82 \\
0 \cdot 27\end{array}$ & $\begin{array}{l}23 \\
18.82 \\
0.93\end{array}$ & $\begin{array}{l}9 \\
9 \cdot 15 \\
0 \cdot 00\end{array}$ & $\begin{array}{l}6 \\
5 \cdot 01 \\
0 \cdot 20\end{array}$ & $\begin{array}{l}11 \\
7 \cdot 92 \\
1 \cdot 20\end{array}$ & $\begin{array}{r}529 \\
528.99 \\
2.91\end{array}$ & 8 & 0.95 \\
\hline $\begin{array}{l}4 \text { Centrencephalic (typical } \\
\text { and atypical) }\end{array}$ & $\begin{array}{l}\mathrm{o} \\
\mathrm{e} \\
\chi^{2}\end{array}$ & $\begin{array}{r}106 \\
99 \cdot 90 \\
0.37\end{array}$ & $\begin{array}{r}107 \\
99.90 \\
0.50\end{array}$ & $\begin{array}{l}57 \\
59 \cdot 40 \\
0 \cdot 10\end{array}$ & $\begin{array}{l}28 \\
34 \cdot 40 \\
1 \cdot 19\end{array}$ & $\begin{array}{l}12 \\
18 \cdot 40 \\
2 \cdot 23\end{array}$ & $\begin{array}{r}15 \\
12 \cdot 20 \\
0.64\end{array}$ & $\begin{array}{l}4 \\
5 \cdot 37 \\
0 \cdot 35\end{array}$ & $\begin{array}{r}8 \\
-7 \cdot 5 \\
0.0\end{array}$ & 7 & $\begin{array}{r}337 \\
-337 \cdot 14 \\
5 \cdot 40\end{array}$ & 7 & 0.70 \\
\hline $\begin{array}{l}5 \text { No convulsions (includ- } \\
\text { ing hemiplegics) }\end{array}$ & $\begin{array}{l}\mathrm{o} \\
\mathrm{e} \\
\chi^{2}\end{array}$ & $\begin{array}{l}81 \\
81.39 \\
0.00\end{array}$ & $\begin{array}{l}68 \\
81 \cdot 39 \\
2 \cdot 20\end{array}$ & $\begin{array}{l}45 \\
50.39 \\
0.58\end{array}$ & $\begin{array}{l}29 \\
25.72 \\
0.42\end{array}$ & $\begin{array}{r}22 \\
15 \cdot 47 \\
2 \cdot 76\end{array}$ & $\begin{array}{l}11 \\
7 \cdot 87 \\
1 \cdot 24\end{array}$ & $\begin{array}{l}7 \\
5 \cdot 37 \\
0 \cdot 49\end{array}$ & $\begin{array}{r}12 \\
-7 \cdot 3 \\
2 \cdot 8\end{array}$ & $\begin{array}{l}9 \\
8\end{array}$ & $\begin{array}{r}275 \\
-274.99 \\
10.57\end{array}$ & 7 & $0 \cdot 10$ \\
\hline $\begin{array}{l}6 \text { Convulsions plus focal } \\
\text { E.E.G. (including hemi- } \\
\text { plegics) }\end{array}$ & $\begin{array}{l}\mathrm{o} \\
\mathrm{e} \\
\chi^{2}\end{array}$ & $\begin{array}{r}47 \\
47 \cdot 03 \\
0 \cdot 00\end{array}$ & $\begin{array}{r}36 \\
47 \cdot 03 \\
2 \cdot 59\end{array}$ & $\begin{array}{l}31 \\
30.53 \\
0.01\end{array}$ & $\begin{array}{r}27 \\
21 \cdot 20 \\
1 \cdot 59\end{array}$ & $\begin{array}{r}16 \\
11 \cdot 20 \\
2 \cdot 06\end{array}$ & $\begin{array}{l}3 \\
6 \cdot 20 \\
1 \cdot 65\end{array}$ & - & $\begin{array}{c}11 \\
-7 \cdot 84 \\
1 \cdot 27\end{array}$ &  & $\begin{array}{r}171 \\
-171 \cdot 03 \\
9 \cdot 17\end{array}$ & 6 & 0.20 \\
\hline $\begin{array}{l}7 \text { Atypical centren- } \\
\text { cephalic }\end{array}$ & $\begin{array}{l}\mathrm{o} \\
\mathrm{e} \\
\chi^{2}\end{array}$ & $\begin{array}{l}71 \\
73 \cdot 85 \\
0 \cdot 11\end{array}$ & $\begin{array}{l}83 \\
73 \cdot 85 \\
1 \cdot 13\end{array}$ & $\begin{array}{r}41 \\
43 \cdot 85 \\
0 \cdot 19\end{array}$ & $\begin{array}{r}21 \\
24 \cdot 18 \\
0 \cdot 42\end{array}$ & $\begin{array}{r}9 \\
12.43 \\
0.95\end{array}$ & $\begin{array}{l}14 \\
9 \cdot 23 \\
2 \cdot 47\end{array}$ & 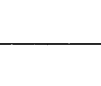 & $\begin{array}{l}8 \\
-9.85 \\
0.35\end{array}$ & 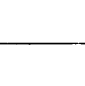 & $\begin{array}{r}247 \\
-247 \cdot 24 \\
5 \cdot 62\end{array}$ & 6 & 0.50 \\
\hline $\begin{array}{l}8 \text { No convulsions plus } \\
\text { normal or borderline } \\
\text { normal E.E.G. }\end{array}$ & $\begin{array}{l}0 \\
\mathrm{e} \\
\chi^{2}\end{array}$ & $\begin{array}{l}29 \\
25 \cdot 32 \\
0.53\end{array}$ & $\begin{array}{r}14 \\
25 \cdot 32 \\
5 \cdot 06\end{array}$ & $\begin{array}{l}21 \\
18 \cdot 32 \\
0 \cdot 39\end{array}$ & $\begin{array}{l}8 \\
9 \cdot 32 \\
0 \cdot 19\end{array}$ & $\begin{array}{l}9 \\
5 \cdot 82 \\
1 \cdot 74\end{array}$ & - & $\begin{array}{r}11 \\
-7 \cdot 8 \\
1 \cdot 2\end{array}$ & 23 & - & $\begin{array}{r}92 \\
-91.99 \\
9 \cdot 14\end{array}$ & 5 & 0.20 \\
\hline $\begin{array}{l}9 \text { Typical centren- } \\
\text { cephalic }\end{array}$ & $\begin{array}{l}\mathrm{o} \\
\mathrm{e} \\
\chi^{2}\end{array}$ & $\begin{array}{l}35 \\
26.07 \\
3.06\end{array}$ & $\begin{array}{l}24 \\
26 \cdot 07 \\
0 \cdot 16\end{array}$ & $\begin{array}{l}16 \\
15.57 \\
0.01\end{array}$ & $\begin{array}{c}7 \\
10.24 \\
1.03\end{array}$ & $\begin{array}{l}3 \\
5 \cdot 99 \\
1.49\end{array}$ &  & $\begin{array}{c}5 \\
-6 \cdot 1 \\
0 \cdot 2\end{array}$ & $\begin{array}{l}0 \\
20\end{array}$ & 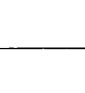 & $\begin{array}{c}90 \\
-90.04 \\
5.95\end{array}$ & 5 & 0.50 \\
\hline $\begin{array}{l}10 \text { Convulsions plus } \\
\text { hemiplegia }\end{array}$ & $\begin{array}{l}\mathrm{o} \\
\mathrm{e} \\
\chi^{2}\end{array}$ & $\begin{array}{r}27 \\
25.63 \\
0.07\end{array}$ & $\begin{array}{l}23 \\
25 \cdot 63 \\
0 \cdot 27\end{array}$ & $\begin{array}{l}13 \\
17 \cdot 13 \\
1 \cdot 00\end{array}$ & $\begin{array}{l}12 \\
10.46 \\
0.23\end{array}$ & $\ldots$ & 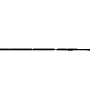 & $\begin{array}{c}16 \\
-12 \cdot 21 \\
1 \cdot 18\end{array}$ & - & $\ldots$ & $\begin{array}{r}91 \\
-91.06 \\
2.75\end{array}$ & 4 & 0.70 \\
\hline $\begin{array}{l}11 \text { Convulsions plus } \\
\text { hemiplegia plus focal E.E.G. }\end{array}$ & $\begin{array}{l}\mathrm{o} \\
\mathrm{e} \\
\chi^{2}\end{array}$ & $\begin{array}{l}15 \\
13.97 \\
0.08\end{array}$ & $\begin{array}{l}11 \\
13.97 \\
0.63\end{array}$ & $\begin{array}{l}8 \\
8 \cdot 97 \\
0 \cdot 10\end{array}$ & $\begin{array}{l}9 \\
6 \cdot 30 \\
1 \cdot 16\end{array}$ & 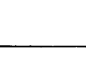 & . & $\begin{array}{c}7 \\
-6.81 \\
-0.01\end{array}$ & _ & 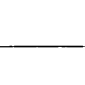 & $\begin{array}{r}50 \\
-50.02 \\
1.98\end{array}$ & 4 & 0.80 \\
\hline
\end{tabular}

SELF CRITICISM

It was mentioned earlier that the Greenwood-Yule method of estimating birth order effect or pregnancy order effect is not without its critics. It is beyond the scope, and, if the truth be known, beyond the capability of the authors of this paper to deal with the mathematical criticisms of the Greenwood-Yule method. However, in defence of our results, we would like to point out that if pregnancy order is not distributed as $\chi^{2}$, as suggested by Halperin (1953), analysing the data by Halperin's recommended alternative would make very little difference to the numerical results and none to the conclusions.

Another, and equally justifiable criticism which has been raised by McKeown and Record (1956), is that the Greenwood-Yule method is best applied to completed families. Some of the families of this study are complete and others are not. For group 1, treating the completed families separately from the incomplete ones, we were unable to find any significant difference. Judging from Table $\mathrm{V}$, there are certainly no obvious differences between the groups in average sibship size, i.e., s, and percentage per pregnancy order. This indicates that the families of the nine convulsant and two non-convulsant groups are equally completed or incompleted. Any resultant bias therefore appears to be equally distributed among the experimental and control groups.

To do away with any bias that may have occurred because of the method of ascertainment we examined the pregnancy order of 231 convulsant siblings of group 1 and 107 convulsant siblings of group 4. It will be recalled that group 1 is a highly heterogeneous group whereas group 4 is a highly specific one, particularly as to the type of electroencephalogram. Table VI indicates that the pregnancy order of the convulsant siblings of these two groups is 
TABLE V

AVERAGE SIBSHIP SIZE AND PERCENTAGE IN EACH PREGNANCY ORDER OF 11 GROUPS OF CONVULSANT AND NON-CONVULSANT PROBANDS

\begin{tabular}{|c|c|c|c|c|c|c|c|c|c|}
\hline & \multirow[t]{2}{*}{ No. } & \multirow{2}{*}{$\begin{array}{l}\text { Average } \\
\text { Sibship } \\
\text { Size }\end{array}$} & \multicolumn{6}{|c|}{ Percentage in Each Pregnancy Order } \\
\hline \multicolumn{2}{|c|}{ Group } & & & 1 & 2 & 3 & 4 & 5 & $6-20$ \\
\hline 1 & Convulsions (including hemiplegics) & 986 & $4 \cdot 07$ & $32 \cdot 8$ & $25 \cdot 8$ & $15 \cdot 7$ & $10 \cdot 9$ & $6 \cdot 4$ & $8 \cdot 5$ \\
\hline 2 & Convulsions (excluding hemiplegics) & 887 & 4.05 & $32 \cdot 5$ & $26 \cdot 0$ & $16 \cdot 0$ & $10 \cdot 7$ & $6 \cdot 3$ & $8 \cdot 4$ \\
\hline 3 & Convulsions plus epileptiform E.E.G. & 569 & $4 \cdot 14$ & $33 \cdot 0$ & $27 \cdot 4$ & $16 \cdot 5$ & $9 \cdot 7$ & $4 \cdot 7$ & $8 \cdot 6$ \\
\hline 4 & Centrencephalic (typical and atypical) & 357 & $4 \cdot 10$ & $35 \cdot 3$ & 30.0 & $16 \cdot 0$ & $7 \cdot 8$ & 3.4 & $7 \cdot 5$ \\
\hline 5 & No convulsions (including hemiplegics) & 293 & 4.09 & $33 \cdot 8$ & $23 \cdot 2$ & $15 \cdot 4$ & $9 \cdot 9$ & $7 \cdot 5$ & $10 \cdot 3$ \\
\hline 6 & Convulsions plus focal E.E.G. (including hemiplegics) & 181 & $4 \cdot 33$ & $31 \cdot 5$ & 19.9 & $17 \cdot 1$ & $14 \cdot 9$ & $8 \cdot 8$ & $7 \cdot 8$ \\
\hline 7 & Atypical centrencephalic & 260 & $4 \cdot 10$ & $32 \cdot 3$ & $31 \cdot 9$ & $15 \cdot 8$ & $8 \cdot 1$ & $3 \cdot 5$ & $8 \cdot 5$ \\
\hline 8 & No convulsions plus normal or borderline normal E.E.G. & 98 & $4 \cdot 35$ & $35 \cdot 7$ & $14 \cdot 3$ & 21.4 & $8 \cdot 2$ & $9 \cdot 2$ & $11 \cdot 2$ \\
\hline 9 & Typical centrencephalic & 97 & 4.09 & $43 \cdot 3$ & $\mathbf{2 4 \cdot 7}$ & $16 \cdot 5$ & $\mathbf{7 \cdot 2}$ & $3 \cdot 1$ & $5 \cdot 2$ \\
\hline 10 & Convulsions plus hemiplegia & 99 & $4 \cdot 22$ & 35.4 & $23 \cdot 2$ & $13 \cdot 1$ & $12 \cdot 1$ & $7 \cdot 1$ & $9 \cdot 1$ \\
\hline 11 & Convulsions plus hemiplegia plus focal E.E.G. & 53 & $4 \cdot 25$ & $34 \cdot 0$ & $20 \cdot 8$ & $15 \cdot 1$ & $17 \cdot 0$ & $5 \cdot 7$ & $7 \cdot 5$ \\
\hline
\end{tabular}

TABLE VI

PREGNANCY ORDER OF CONVULSANT SIBLINGS OF TWO GROUPS OF CONVULSANT PROBANDS

Pregnancy Order d.f. $\quad P$

$1 \quad 2 \quad 3$

$3 \quad 4$

5

5

67

7

Group 1 Convulsions (including

$\begin{array}{lll}53 & 62 & 57 \\ 52.58 & 52.58 & 46\end{array}$

e

0.00

Group 4 Centrencephalic (typical o and atypical)

\begin{tabular}{lrrr} 
o & \multicolumn{1}{c}{22} & \multicolumn{1}{c}{27} & \multicolumn{1}{l}{25} \\
e & 24.55 & 24.55 & 23.05 \\
$\chi^{2}$ & 0.26 & 0.24 & 0.16
\end{tabular}

19

$14 \cdot 72$
$1 \cdot 24$

28
$30 \cdot 75$
$0 \cdot 25$
19
$14 \cdot 72$
$1 \cdot 24$

9
$18 \cdot 50$
$4 \cdot 88$
7
$8 \cdot 72$
0.34

11
$12 \cdot 50$
0.
5
5
0

randomly distributed $(P=0.10$ and $P=0.70)$.

The astute reader may have noted that in Table II there is a consistent tendency for the proband to be among the later born when $s$ is 4 or more. This tendency is also present for the non-convulsant probands of Table III. In part, the explanation lies in the fact that the probands are ascertained at the Montreal Children's Hospital and are unlikely to be over 16 years of age. A proband who is 16 years or less is unlikely to have more than 15 younger siblings. If a period of 18 months is allowed between pregnancies, the proband cannot have more than 10 younger siblings. This is indeed what the 'scatter diagrams' of Tables II and III show, i.e., up to about $\mathbf{s}=3$, distribution is as expected but after $\mathrm{s}=3$ the distribution tends to favour the higher pregnancy orders. Due to the small number of such families, the effect is relatively unimportant and has not been reflected in the overall results.

Would the results regarding pregnancy order be the same for adult epileptics as for child epileptics? All indications derived from this study tend to suggest an affirmative answer. By way of confirmation, we recently analysed the pregnancy order of a heterogeneous group of 49 adult epileptics whose sibships are completed and found a random distribution $(\mathbf{P}=\mathbf{0} \cdot 10)$.

Finally, one may ask what would happen if the miscarriages are omitted from the present data and birth order effect was looked for only among live-

born children. On the basis of the work of one of ou? colleagues, Dr. Dorothy Warburton, who found the miscarriage frequency was not related to pregnancos order but was fairly stable around $14 \%$ for all rankg (1961), we anticipated no appreciable effect. Ag. analysis of the various convulsant and contro $\vec{\varnothing}$ groups failed to reveal any significant birth order effect when liveborn children only are considered. (However, the slight but distinct tendency for the proband to be among the later born when $s$ is large was again present.) But irrespective of the outcome of such an analysis, we would still hold to our original contention that looking for birth order effect by analysing live births only is not sound.

In closing, we wish to make it abundantly clear that we are not suggesting that birth trauma or other prenatal and perinatal factors are incapable of producing epilepsy in certain instances. What we are suggesting is that if and when these factors do produce epilepsy they are related neither to birth order nor to pregnancy order. For the sake of better understanding, we are even willing to concede that if birth trauma is more likely to occur with first born than with later born, then the first born would have a slightly increased chance of developing epilepsy. However, this increased probability must be very slight and, if really there, it could not be detected in No our data of 986 convulsant probands. It is certainly not of the magnitude suggested by certain investigators. The slightly better obstetric care and concern 
that is shown to the primigravida more than compensates for any increased risk that the first born may have of getting epilepsy.

\section{CONCLUSIONS: FOR OR AGAINST?}

When the parity of 1,279 probands was considered from two points of view, birth order (pregnancies resulting in live infants only) and pregnancy order (all pregnancies irrespective of outcome), it was found that birth order was not in agreement with pregnancy order in $22.4 \%$ of the cases. It is of great significance that this error is neither of the same magnitude nor in the same direction for all birth orders. For birth order I the error is $12.1 \%$ and increases rapidly so that by birth order VII it is $58.8 \%$. Birth orders I to III over-represent pregnancy orders 1 to 3 and birth orders IV to XVI underrepresent pregnancy orders 4 to 17 by an equal amount.

On the basis of the presence or absence of convulsions and on the type of electroencephalogram, the pregnancy order of nine groups of convulsant and two groups of non-convulsant probands was analysed. (It is of particular interest that one of the convulsant groups involved brain-injured children whose cerebral palsy was substantiated by the presence of a focal electroencephalogram.) In none of these 11 groups was pregnancy order found to be other than randomly distributed.
When live borns only were considered, an analysis of the various convulsant and control groups failed to reveal any birth order effect.

It is suggested that profound conclusions based on the assumed association of birth order and/or pregnancy order with epilepsy be withheld until such an association has been demonstrated. The present study has failed to demonstrate such an association.

We wish to express our thanks to Dr. Dorothy Warburton, Department of Genetics, McGill University, who helped us unravel some of the mathematical intricacies of the statistical techniques used.

This investigation was supported by PHS-B-706-C8 research grant from the National Institute of Neurological Diseases and Blindness, Public Health Service, U.S.A., and by grant 604-13-66 from the Department of National Health and Welfare, Canada.

\section{REFERENCES}

Annotation (1962). Lancet, 1, 790.

Colver, T., and Kerridge, D. F. (1962). J. Neurol. Neurosurg. Psychiat., 25, 59.

Greenwood, M. , and Yule, G. U. (1914). J. roy. statist. Soc., 77, 179.

Haldane, J. B. S., and Smith, C. A. B. (1948). Ann. Eugen. (Lond.), $14,117$.

Halperin, M. (1953). Ibid., 18, 99.

McKeown, T., and Record, R. G. (1956). Amer. J. hum. Genet., 8, 8. Metrakos, K., and Metrakos, J. D. (1961). Neurology (Minneap.), $11,474$.

Warburton, D. (1961). Ph.D. Thesis, McGill University. 